\title{
Integrated sizing and scheduling of wind/PV/diesel/battery isolated systems
}

\author{
André Malheiro a, *, Pedro M. Castro ${ }^{b}$, Ricardo M. Lima ${ }^{c}$, Ana Estanqueiro ${ }^{\mathrm{a}, \mathrm{d}}$ \\ a Departamento de Engenharia Geográfica, Geofísica e Energia, Faculdade de Ciências, Universidade de Lisboa, 1749-016 Lisboa, Portugal \\ ${ }^{\mathrm{b}}$ Centro de Investigação Operacional, Faculdade de Ciências, Universidade de Lisboa, 1749-016 Lisboa, Portugal \\ ${ }^{\mathrm{c}}$ Computer, Electrical and Mathematical Sciences and Engineering Division, King Abdullah University of Science and Technology (KAUST), Thuwal 23950- \\ 6900, Saudi Arabia \\ d Unidade de Análise Energética e Redes, Laboratório Nacional de Energia e Geologia, 1649-038 Lisboa, Portugal
}

\section{A R T I C L E I N F O}

\section{Article history:}

Received 14 June 2014

Accepted 28 April 2015

Available online 22 May 2015

\section{Keywords:}

LCOE

Isolated hybrid systems

Sizing optimization

Renewable energies

\begin{abstract}
A B S T R A C T
In this paper we address the optimal sizing and scheduling of isolated hybrid systems using an optimization framework. The hybrid system features wind and photovoltaic conversion systems, batteries and diesel backup generators to supply electricity demand. A Mixed-Integer Linear Programming formulation is used to model system behavior over a time horizon of one year, considering hourly changes in both the availability of renewable resources and energy demand. The optimal solution is achieved with respect to the minimization of the levelized cost of energy (LCOE) over a lifetime of 20 years. Results for a case study show that the most economical solution features all four postulated subsystems.
\end{abstract}

() 2015 Elsevier Ltd. All rights reserved.

\section{Introduction}

The world energy demand is increasing at a larger rate than the growth of human population [1]. It is expected that the highest increase will occur in the developing countries, where 1.4 billion people still do not have access to energy services [2]. The lack of an interconnected electrical grid and synchronous power system in remote areas might be overcome by the installation of isolated micro-grids (electric islands) fed by endogenous resources. These type of isolated systems have been implemented using only diesel generators or combined with one renewable source, but due to the growing maturity of wind and photovoltaic systems, and high diesel costs, these traditional systems are being updated in order to incorporate multiple renewable technologies [3] [4].

The systematic design and operation of hybrid systems by optimization tools is driven by the need to overcome the complexity of decision making in the presence of high variability of renewable resources, variable energy demand profile, different performance and cost characteristics of equipment.

\footnotetext{
* Corresponding author. Tel.: +351969 855242.

E-mail address: andrefmalheiro@gmail.com (A. Malheiro).
}

The evaluation of hybrid systems has been reported using different performance models, optimization software tools, and techniques [5] [6]. The methodology proposed in Ref. [7] uses a dynamic programming model to determine the optimal operating strategy for a wind-diesel-battery system during $24 \mathrm{~h}$. The design optimization of a Wind/Diesel/Battery system based on construction of trade-offs curves is presented in Ref. [8] so as to define the diesel and battery system capacity. In addition, the economics of charging the batteries with diesel power is discussed comparing alternative models for dispatch strategies. In Ref. [9], the authors propose a non-linear constrained model to find the optimal combination of energy components (hydro, wind, solar, diesel and batteries) using an iterative method and a QuasiNewton algorithm. Several individual combinations are compared, and the best is chosen. A sizing method for an isolated grid with diesel is presented in Refs. [10] and [11]. The authors have used an optimization framework based on genetic algorithms to select the optimal wind turbine, PV rated power, nominal capacity for the battery energy storage system, and inverter rating. The benefits of introducing renewables compared to a $100 \%$ diesel system are then measured. However, in both works, the diesel generators are outdated and the re-size is not evaluated for an optimal solution. A similar approach is followed in Ref. [12] but without the diesel backup. A methodology based on a multi-objective 